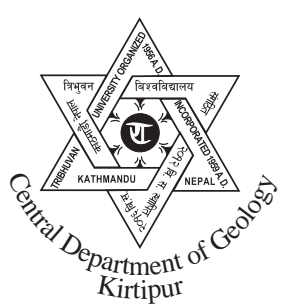

Bulletin of the Department of Geology

Bulletin of the Department of Geology, Tribhuvan University, Kathmandu, Nepal, Vol. 14, 2011, pp. 59-66

\title{
Palynological assemblages from the Late Pleistocene sediments of the Patan Formation in Kathmandu Valley and their climatic implications
}

\author{
Khum Narayan Paudayal \\ Central Department of Geology, Tribhuvan University, Kirtipur, Kathmandu, Nepal
}

\begin{abstract}
Palynological investigation of ten samples obtained from a drill core belonging to the Late Pleistocene deposits of the Patan Formation in the Kathmandu Valley revealed 40 plant species belonging to 22 families. The gymnosperms are represented by Abies, Picea, Pinus spp. (P. roxburghii and P. wallichiana) and Tsuga sp. The angiosperm tree and shrubs are represented by genera Quercus (Q. semecarpifolia, Q. lanata, Q. leucotricophora and Q. lamellosa and Q. glauca), Castanopsis, Alnus, Betula, Carpinus, Juglans, Myrica, Ulmus, Ilex, Strobilanthes, Elaeagnus and families Meliaceae, Oleaceae, Ericaceae, Poaceae, Compositae, Caryophyllaceae, Chenopodiaceae, Apiaceae, and Dipsacaceae. Similarly the wetland and aquatic plants are represented by Polygonun, Myriophyllum and Trapa. The presence of significant number of pteridophytes indicates humid and damp environment at the periphery of the lake and surrounding forest floor. The pollen assemblage suggests that the Patan Formation was deposited under humid subtropical climate except at the middle part which indicates of warm temperate climatic condition. The result obtained from the recent surface samples analysis and its comparison with fossil assemblages show that modern pollen spectra are not different with the fossil assemblages. This justifies that the fossil palynomorphs are local and it denies the influence of exotic pollen.
\end{abstract}

\section{INTRODUCTION}

Kathmandu Valley hosts more than $600 \mathrm{~m}$ thick deposits of Plio-Pleistocene lacustrine sediments (Moribayasi and Maruo 1980) providing a unique opportunity to study the climate change based on plant microfossils. Many authors have investigated the soft sediments of this valley and tried to understand the climate change on the basis of palynological assemblages (Franz, and Kral 1975; Kral and Havinga 1979; Yoshida and Igarashi 1984; Igarashi et al. 1988; Vishnu-Mittre and Sharma 1984; Nakagawa et al. 1996; Fujii and Sakai 2001, 2002; Paudayal and Ferguson 2004; Paudayal 2005, 2006; Bhandari and Paudayal 2007). Most of the investigations have been carried out with the samples taken from the surface exposure, cliffs or sand mining pits. Investigation based on drilled core samples was also made by some authors (Fujii and Sakai 2001, 2002). Due to complex sedimentary environment and lack of enough chronological information, understanding the climatic

\footnotetext{
*Corresponding author:

E-mail address: khum99@gmail.com
}

history is becoming difficult for the scientists working in this area. This study is based on the drill core slime obtained from the central part of the basin belonging to the Patan Formation.

\section{GEOLOGY}

The Kathmandu Valley sediments have been divided into eight different stratigraphic units (Yoshida and Igarashi 1984; Yoshida and Gautam 1988). The oldest is the Lukundol Formation, mostly lacustrine in nature, ranging in age from Upper Pliocene to Lower Pleistocene, followed by intermediate gravel deposits such as Chapagaon, Boregaon and Pyanggaon deposits developed in the course of tilting of the lake due to activation of Main Boundary Thrust (MBT) towards the south margin. Tilting of this lake towards northern direction and further activation of MBT created a new fluvially dominated sedimentary environment. Occasional depositional pause created lacustrine environment periodically within the fluvial cycles. The younger sediments thus deposited in the northern part are the Gokarna Formation, Thimi Formation, Patan Formations and Recent terrace deposits ranging in age 


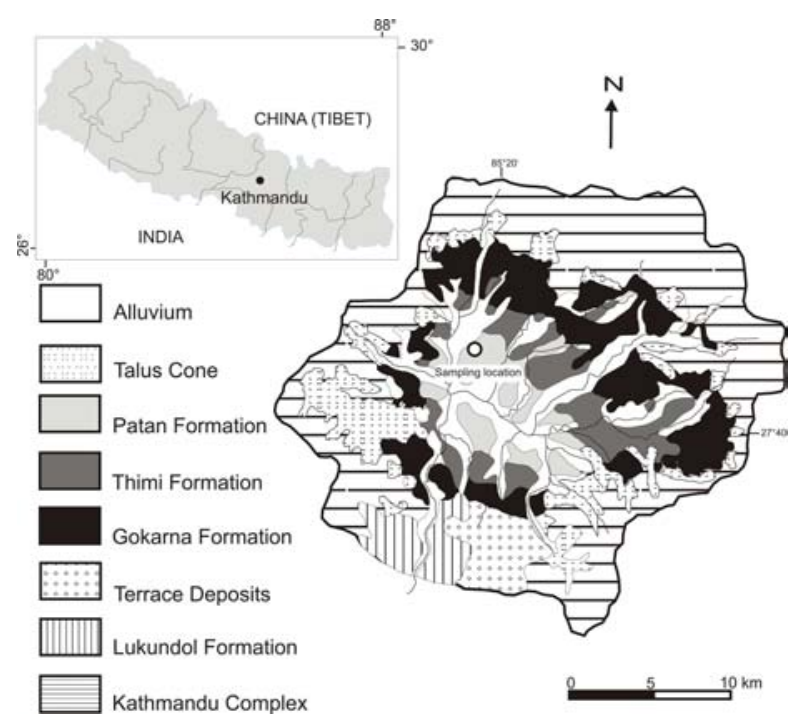

Fig. 1 Geology of the Kathmandu Valley with the location of sampling site. (after Yoshida and Igarashi 1984, Yoshida and Gautam 1988).

from Late Pleistocene to Holocene (Fig. 1). Evaluation and revision of the fluvio-lacustrine sediments from the northern part of the Kathmandu Valley is still in progress on the basis of composite facies analysis, radiometric dating and paleomagnetic polarity data (Sakai et al. 2008). The chronology of the northern part is still not well established because of different sets of radiocarbon dating results obtained from the same sections by different authors (Yoshida and Igarashi 1984; Paudayal and Ferguson 2004; Sakai et al. 2008).

The Patan Formation lies at the core of Kathmandu City. It is composed of alternating fluvio-lacustrine sand, gravel and silt or clay. The lithology of this formation is quite similar to that of the Gokarna Formation showing dominating deltaic environment. The relative height of the Patan Formation is 20 to 50 $m$ above the Bagmati River bed. As the Patan Formation lies in urban area it is therefore difficult to get a surface exposure. Therefore a total of 10 samples collected from $20 \mathrm{~m}$ long slime drilled at Bir Hospital compound. The sampling location lies at an altitude of $1304 \mathrm{~m}$ at the co-ordinates $27^{\circ} 42^{\prime} 18^{\prime \prime} \mathrm{N}$ and $85^{\circ} 18^{\prime} 48^{\prime \prime} \mathrm{E}$. The detailed litholog of the slime shows an alternation of silt, silty clay and clay mostly dominated by coarse sand deposits (Fig. 2). The radiocarbon age dating made by different authors show that the age of the formation ranges from 14,000 to 19,000 years before present (Table 1).
In order to understand the frequency and distribution of modern pollen that are likely to be deposited in the sediments, 50 surface samples were collected from the northern (Balaju, Sundarijal and Guheshwari) and southern (Godawari) parts of the Kathmandu Valley. These samples were moss bolsters from the forest floor, fine silt and clay sediments from the ditches, swamps and river banks.

\section{METHODOLOGY}

The samples were prepared in the laboratory following the methods described by Zetter (1989), and Ferguson at al. (2007). In order to remove any contamination from the recent pollen from the atmosphere the samples were cleaned with scrapper, crushed them to powder and treated with Hydrochloric acid $(\mathrm{HCl})$ to remove any carbonate contain in it. This was followed by the treatment with Hydrofluoric acid

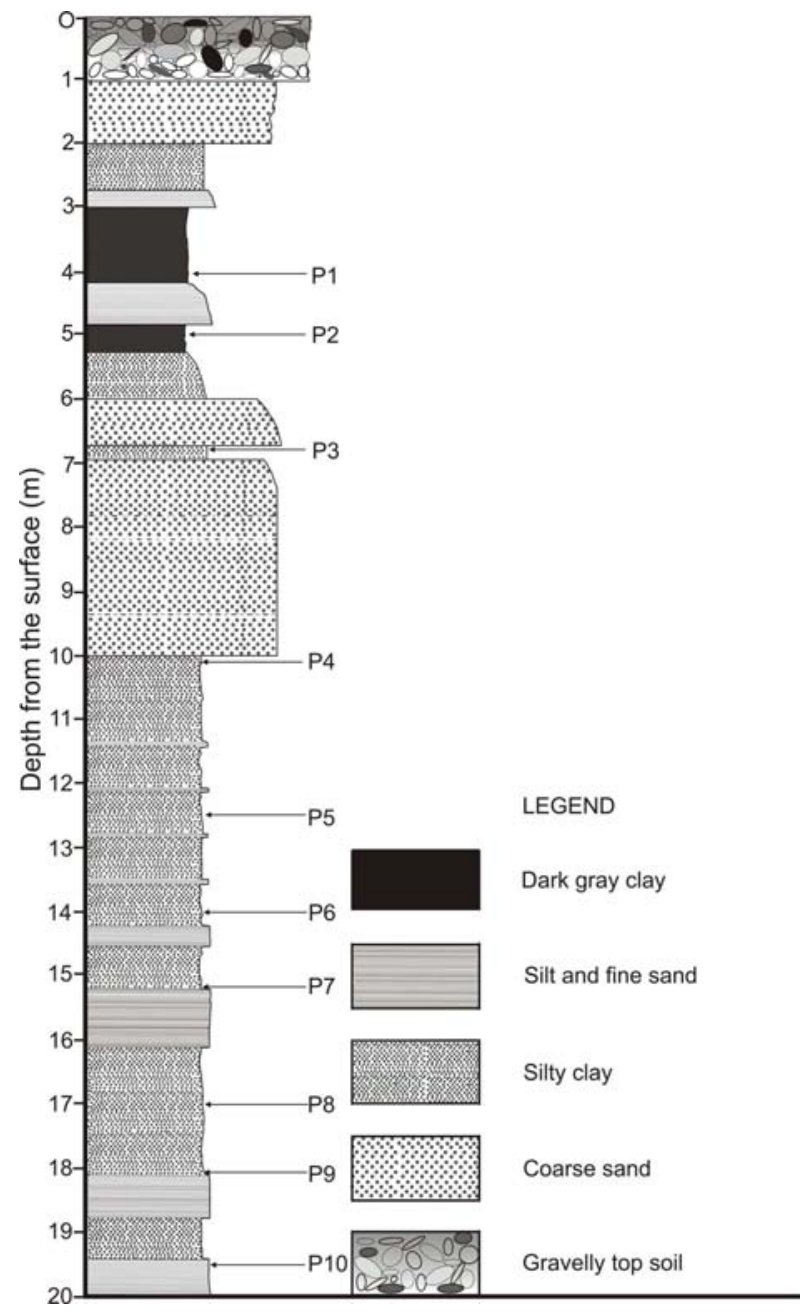

Fig. 2 Lithological details of the Patan Formation. 
Table 1: Radiocarbon age of the Patan Formation with the location of the sampling sites.

\begin{tabular}{lll}
\hline $\begin{array}{l}\text { Radiocarbon age (years BP) } \\
\text { and laboratory Codes) }\end{array}$ & $\begin{array}{l}\text { Author and the year of } \\
\text { publication }\end{array}$ & $\begin{array}{l}\text { Sample } \\
\text { site }\end{array}$ \\
\hline $14,050 \pm 250($ VRI-390) & Franz and Kral (1975) & Airport \\
$17,090 \pm 1050($ Gak-6193) & Yonechi (1976) & Teku \\
$14,890 \pm 820($ Gak-6194) & Yonechi (1976) & Teku \\
$18,970 \pm 1480($ Gak-6195) & Yonechi (1976) & Teku \\
$13,140 \pm 380($ Gak-6200) & Yonechi (1976) & Koteswar \\
$11,070 \pm 290($ Gak-6201) & Yonechi (1976) & Koteswar \\
$14,579 \pm 380 / 360($ TH-729) & Yoshida and Igarashi (1984) & Pashupati \\
$14,190 \pm 110($ JNC-4658) & Sakai et al. (2008) & Sinamangal \\
\hline
\end{tabular}

(HF) and boiled for half an hour to remove silicate minerals from the samples. The samples were then forwarded to chlorination and acetolysis, then washed with distilled water and glacial acetic acid in each step and centrifuged at the rate of $2000 \mathrm{rpm}$ for 2-3 minutes to remove the finer fraction of the sediments from the sample. Finally the organic material was separated from the inorganic residue using heavy liquid Zinc Chloride $\left(\mathrm{ZnCl}_{2}\right)$. The residue thus obtained was washed several times with distilled water and mixed with glycerin for microscopic observation.

The modern surface samples (sediments collected from the river banks) were also prepared following the same procedure. The moss samples were washed in water and sieved to separate undesired moss masses. The water with the suspended organic matter was centrifuged at $1500 \mathrm{rpm}$ for 30 seconds and decanted. By repeating this process several times a considerable amount of organic residue was collected in a test tube. The residue was washed with glacial acetic acid and centrifuged three times before preparing for the chlorination and acetylation. It was not necessary to make heavy liquid separation as the residue was devoid of mineral particles. The final residue was washed with water for twice and mixed with glycerin for microscopic examination. In total of 400 pollen and spores were point counted from each sample in a NIKON OPTIPHOT-2 Light Microscope under 10x, $40 x$ or $80 x$ objectives. In order to identify the key climate indicating genera such as Pinus and Quercus, at least 100 pollen from each sample were examined to their species level. The Pinus pollen were identified under Light Microscope (LM) while identification of Quercus pollen was made under Jeol JSM 6400 Scanning Electron Microscope (SEM) at $10 \mathrm{kV}$ at different magnifications and orientations.
Interpretation of Quaternary pollen data is mainly based on pollen diagrams. A pollen diagram consists of a series of graphs that are generally prepared on the basis of the percentage of all available (or major) pollen taxa in the total pollen count of an individual sample. The abscissa represents the percentages of all available (or major) pollen types and the ordinate represents the depth of the individual sample from the surface and thus the chronology of the stratigraphic column (Figs. 3 and 4). The graphical representation of pollen data was made by a computer software TILIA version 2.0.b.4.

\section{THE FOSSIL POLLEN ASSEMBLAGES FROM THE PATAN FORMATION}

Based on its palynological assemblages, the Patan Formation has been divided into three zones, namely PATAN-I, PATAN-II and PATAN-III in ascending orders (Fig. 3). The composition of the palynomorphs from each zones are described below. The pollen percentage of two key genera Pinus and Quercus are also used to reconstruct the climate during the deposition of the Patan Formation (Fig. 4).

\section{PATAN-I}

This zone is characterized by high percentages of Quercus (33-38\%) and low values of Pinus (5-6\%). Pinus wallichiana is the predominant pine species. Other Pinaceae (Abies spectabilis, Picea smithiana, Tsuga dumosa) are each represented by less than $1 \%$. Quercus lamellosa is the commonest oak, but $Q$. lanata (20-26\%) and Q. leucotrichophora (14\%) are also well represented. Although $Q$. semecarpifolia initially constituted $18 \%$ of the oak sum, this value subsequently fell to $2 \%$. Alnus (3\%), Betula (3\%), Carpinus (1-2\%), Castanopsis (1-2\%), Ilex (1\%), Myrica (1-3\%), Ulmus $(<1 \%)$, Meliaceae $(<1 \%)$ and Oleaceae $(1 \%)$ are the main constituent of other angiosperm trees and shrubs. The terrestrial herbs are dominated by the Poaceae (16\%), Artemisia (4\%), other Compositae (3\%) and the Caryophyllaceae (1\%). Aquatic herbs such as Polygonum and Myriophyllum were represented by less than $2 \%$. Pteridophyte spores are dominating reaching the value by $46-55 \%$.

\section{PATAN-II}

The contribution of Pinus increases to $11-13 \%$ in this zone. Of the two pine species, $P$. wallichiana is the more numerous. The remaining Pinaceae continue 


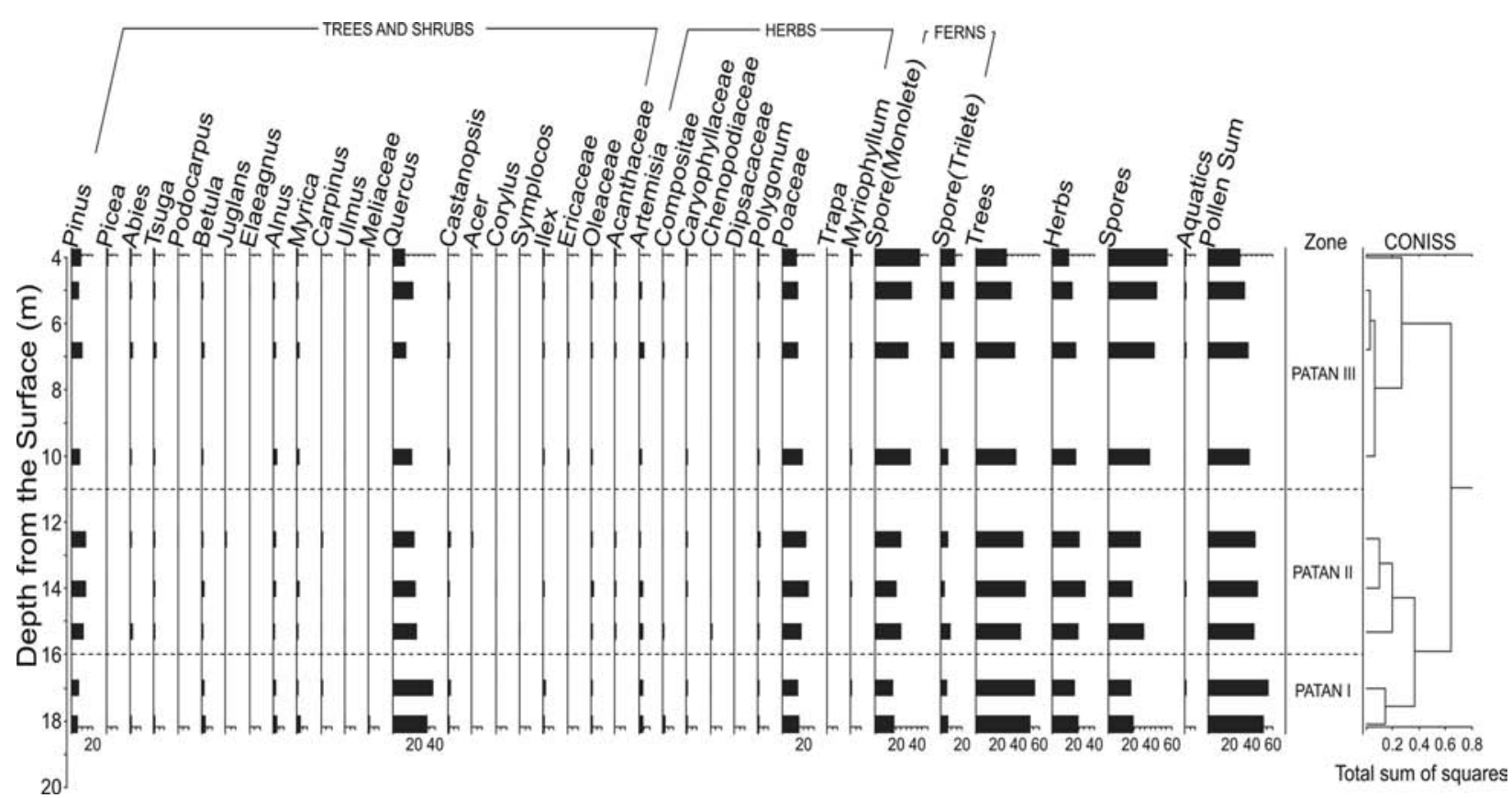

Fig. 3 Pollen diagram of the Patan Formation.

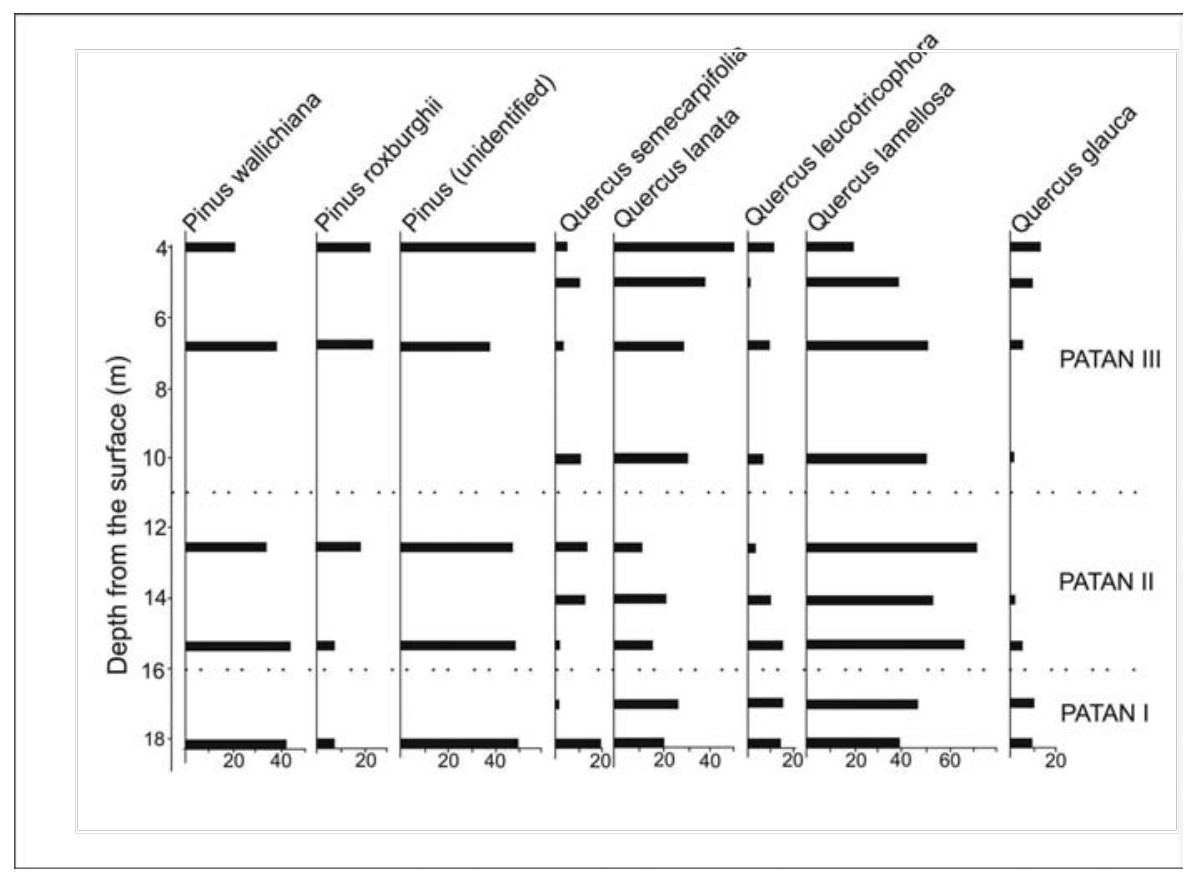

Fig. 4 Pollen diagram of the individual species Pinus and Quercus (P-Q diagram) from the Patan Formation.

to be poorly represented by Abies spectabilis (1-2\%), Picea smithiana $(<1 \%)$, and Tsuga dumosa $(<1 \%)$. Although Quercus pollen is less common (20-22\%), $Q$. lamellosa (53-71\% of the oak sum) remains the predominant species, followed by $Q$. lanata (11-21\%). $Q$. leucotrichophora (3-13\%) and $Q$. semecarpifolia $(2-13 \%)$ fulfil a subordinate role. Other shrubs and trees such as Alnus (1-2\%), Betula (1-3\%), Carpinus $(<1 \%)$, Castanopsis (<2\%), Myrica (1-2\%), Ulmus $(<1 \%)$, Ericaceae $(<1 \%)$ and Oleaceae $(1-2 \%)$ represent only minor components. With the exception of the Poaceae $(18-25 \%)$, the herbs are rare which are represented by Acanthaceae $(<1 \%)$, Artemisia $(1-4 \%)$, other Compositae $(<1 \%)$, Caryophyllaceae $(1 \%)$, 
Chenopodiaceae $(1 \%)$ and Dipsacaceae $(<1 \%)$. Fern spores represent $22-32 \%$ of the total pollen sum.

\section{PATAN-III}

Pinus values fall to $6-10 \%$, with $P$. wallichiana and $P$. roxburghii now represented in more or less equal proportions. Abies spectabilis (1-2\%) and Picea smithiana $(<1 \%)$ have similar values to PATAN-II, but Tsuga dumosa is slightly better represented (1-2\%) than before. Although its percentage continues to fall, Quercus is still the commonest tree (12-19\%). Q. lamellosa was initially the commonest species, but is replaced by $Q$. lanata in the course of this zone. $Q$. leucotrichophora and Q. semecarpifolia, which are present throughout, only played a minor role. Other trees and shrubs such as Alnus (1-3\%), Betula (1-2\%), Castanopsis (1-2\%), Elaeagnus ( $<1 \%)$, Ilex $(<1 \%)$, Myrica (1-2\%), Ericaceae (1-2\%) and Oleaceae (1-2\%) were poorly represented. The herbs continue to be dominated by the Poaceae (13-19\%). The remaining terrestrial herbs, such as Artemisia (1-4\%), other Compositae $(<1 \%)$, Caryophyllaceae $(<1 \%)$, Chenopodiaceae $(<1 \%)$ and Dipsacaceae $(<1 \%)$ as well as the aquatic herbs, i.e. Myriophyllum (1-2\%) and Polygonum (1-2\%) represent minor elements. In the course of the zone the ferns increase from 39 to $55 \%$.

\section{MODERN POLLEN SPECTRA FROM THE KATHMANDU VALLEY FLOOR}

In order to reconstruct the palaeovegetation, fossil pollen assemblages are compared with that of modern pollen assemblages. This can be successfully done when a modern analogue of the past vegetation exits (Bos 1998). The surface sample studies are an essential stage in the interpretation of fossil assemblages (Birks and Gordon 1985). Small waterlogged locations, such as ditches and moats are able in environmental archaeological studies because of their capacity to preserve a range of useful materials, including pollen and spores (Moore et al. 1991). Interpretation of fossil pollen data requires a thorough knowledge of the present day ecology of the taxa involved. However, the comparison of modern pollen assemblages with that of fossil pollen assemblage is more complex because of factors such as pollen production, meteorological factors influencing pollen transportation and physical, biological and chemical conditions of the depositional environment which affect deposition and preservation of the pollen. In this study, the comparative approach of modern pollen data with that of fossil pollen data is aimed to establish the similarities between modern and fossil spectra, so that the latter can be interpreted in terms of modern analogues. If similarities exist between modern and fossil assemblages, it is likely that the spectra were produced by broadly similar vegetation. Thus, a modern vegetation analogue can be proposed for the past vegetation. Such comparison provides a factual and repeatable basis for vegetation reconstruction (Birks and Gordon 1985). The pollen data obtained from the modern surface samples in the Kathmandu Valley floor clearly indicates the source of pollen, their dispersal mechanism and their spatial relation to the fossil pollen assemblages (Fig. 5).

\section{Northern part of the Kathmandu Valley}

\section{Sundarijal area}

Surface samples collected from forest floor, open pits and from the bank of the Bagmati River comprised both sediments as well as moss cushions. Out of ten samples collected from this area, only two moss samples (SU-M1 and SU-M2) and three surface sediment samples (SU-S1, SU-S2, and SU-S4) yielded enough pollen for quantitative analysis. The surface samples from Sundarijal area are characterized by high percentage of Pinus (12-43\%), Alnus (23-55\%) and other tree pollen such as Abies (1\%), Betula (1-2\%), Elaeagnus (<1\%), Quercus $(2-11 \%)$, Castanopsis $(1-7 \%)$, Symplocos (1\%), Ericaceae $(<1 \%)$, Artemisia (1\%), other Compositae (1-2\%), Caryophyllaceae (1-2\%), Poaceae (1-22\%) and Pteridophyte spores (14-21\%).

\section{Guheshwari area}

Out of five samples from the Guheshwari area, two surface samples were found to be rich enough to be worth counting. One of these was a sediment sample (GU-S1) from the bank of the Bagmati River; another was a moss cushion (GU-M2) from the forest floor behind the Guheshwari temple. The Guheshwari surface samples were more or less similar to those from Sundarijal with the exception of the percentage of Poaceae. The major pollen types found in this area were Pinus (12-17\%), Alnus (8-12\%), Quercus (17-23\%), Abies (1-3\%), Poaceae (16-20\%), Oleaceae (2-4\%), Castanopsis (1-2\%), Acanthaceae (<1\%), Artemisia (1-18\%), Chenopodiaceae $(<3 \%)$ and Pteridophytes (13-15\%). 


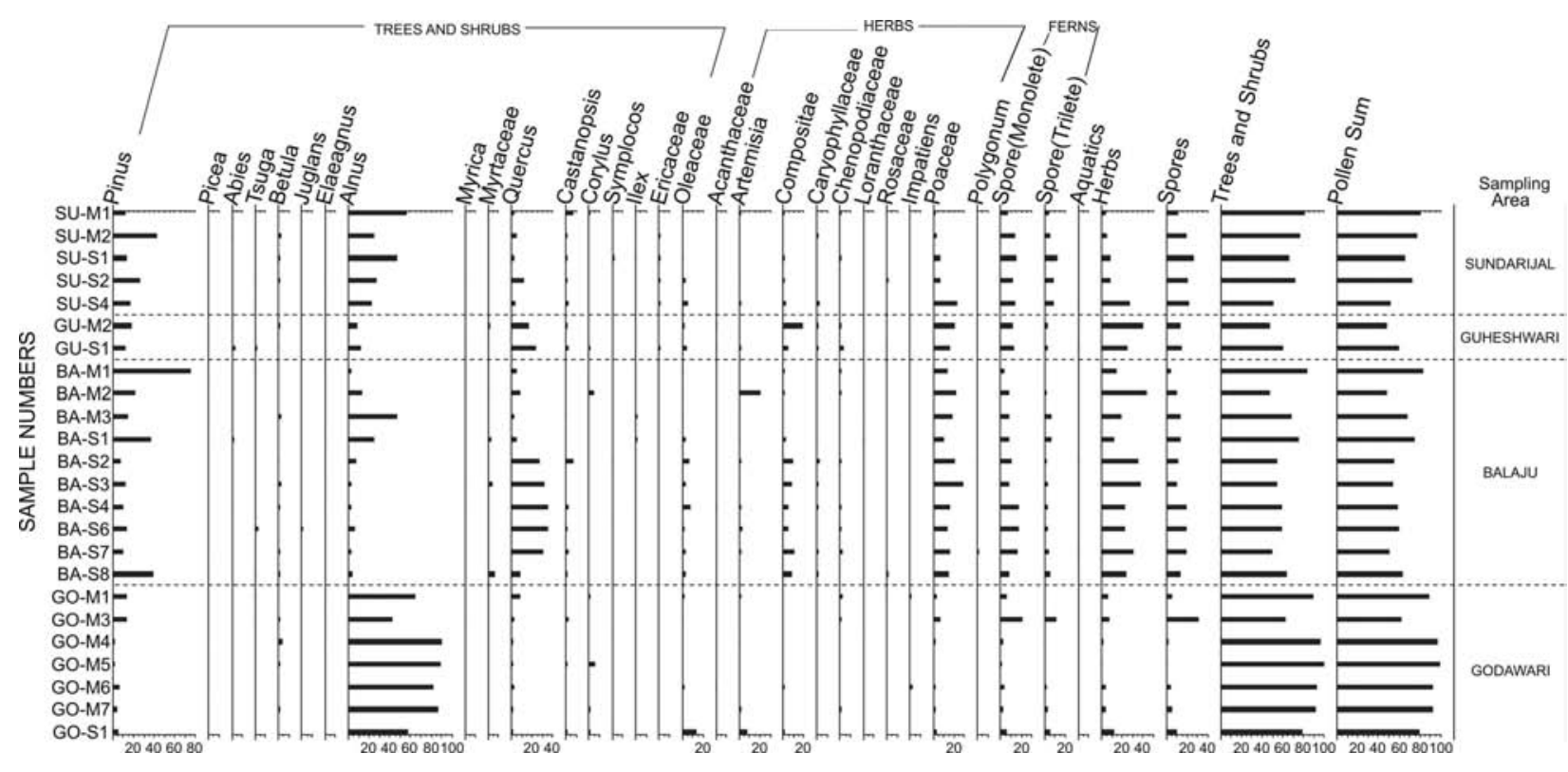

Fig. 5 Recent pollen diagram from the Kathmandu Valley.

\section{Balaju area}

Fifteen samples were collected from the Balaju area of which ten samples were found to be rich in pollen. Three of these samples (BA-M1, BA-M2 and BA-M3) were moss cushions, while seven samples (BA-S1, BA-S2, BA-S3, BA-S4, BA-S6, BA-S7 and BA-S8) were sediment from ditches and small pits. In these samples relatively high percentages of Quercus pollen were found. Other major types of pollen consist of Pinus, Alnus, Poaceae and Pteridophytes. However, percentages of the major pollen types were not found to be uniform throughout.

The two moss samples (BA-M2 and BA-M3) showed relatively high percentages of Pinus (14-21\%), while in BA-M1, 75\% of the total pollen count consisted of Pinus. The percentage of Quercus in moss samples was 2-8\%. In samples BA-M1 and BA-M2 the percentage of Alnus was lower (2-13\%) than in sample BA-M3 (47\%). The sediment samples (BAS1, BA-S2, BA-S3, BA-S4, BA-S6, BA-S7 and BAS8) were found rich in Pinus (7-36\%) followed by Quercus (5-35\%) and Alnus (2-25\%) in Balaju area. The trees and shrubs were represented by Abies (1$2 \%)$, Tsuga (<1\%), Betula (1-2\%), Myrtaceae (1-6\%), Castanopsis (1-6\%), Corylus (1-4\%), Symplocos (1\%) and Oleaceae (1-8\%). The herbs were dominated by Poaceae $(9-22 \%)$. The other herbaceous plants found were Acanthaceae (<1\%), Artemisia $(1-20 \%)$, other
Compositae (1-10\%), Caryophyllaceae (1-2\%), Chenopodiaceae $(1-2 \%)$ and Loranthaceae $(<1 \%)$. The percentage of Pteridophyte spores ranges between 4$19 \%$ of the total pollen count.

\section{Southern part of the Kathmandu Valley}

\section{Godawari area}

Out of twenty samples collected from the Godawari area, only seven samples were found to be rich enough in pollen for a quantitative study. Out of seven rich samples, six (GO-M1, GO-M3, GO-M4, GO-M5, GOM6 and GO-M7) were moss cushions and GO-S1 was a sediment sample.

The main pollen constituents of these samples were Alnus and Pinus. Among these two, Alnus highly dominates the total pollen sum ranging in between 4290\% while the percentage of Pinus ranges in between $1-13 \%$. Other gymnosperms such as Picea, Abies and Tsuga were virtually lacking in these surface samples. Other trees and shrubs were Betula (1-4\%), Quercus (1-8\%), Castanopsis (1-2\%), Corylus (81-5\%) and, Oleaceae (1-13\%). Herbaceous plants consist of Poaceae (1-6\%), Caryophyllaceae $(<1 \%)$ and, Impatiens (1$2 \%)$. Pteridophyte spores covered $30 \%$ of the total pollen count.

Comparison of pollen assemblage obtained from the modern surface samples with that of fossil pollen 
assemblage showed an interesting result. Most of the elements of modern analogue were also present in the fossil assemblages. The modern surface samples revealed the high percentages of Pinus and Quercus in the northern part, while percentages of Alnus are higher in the southern part of the Kathmandu Valley. The percentage of Alnus in the Patan Formation was very low than in the modern surface samples. The high percentage of few species may indicate the presence of the source plant very close to the surface samples. This is an indication of the fossil assemblages which reflect the local vegetation rather than regional vegetation. Analysis of modern surface sample also confirmed the absence of exotic pollen in the pollen assemblages.

\section{DISCUSSION AND CONCLUSION}

Different species of Pinus and Quercus are distributed in particular climate zones in Nepal (Stainton 1972). Pinus wallichiana grows from $1800 \mathrm{~m}$ up to $4100 \mathrm{~m}$ in cold areas (on south slopes) while $P$. roxburghii is distributed from $1100 \mathrm{~m}$ to $2100 \mathrm{~m}$ in warmer areas. Thus, the dominance of either of these two species can predict the climate in which they were growing during the geological past. Similarly different Quercus species grow under different climatic conditions. Quercus semecarpifolia inhabits cold areas mostly on south-facing slopes (altitudes between 1700 m-3800 m), whereas Q. lanata (between 1500 m-2900 $\mathrm{m}$ ) and Q. leucotrichophora (between $1500 \mathrm{~m}-2400$ m) grow in relatively warm areas. Another oak $Q$. lamellosa (between $1600 \mathrm{~m}-2800 \mathrm{~m}$ ) prefers subtropical to warm temperate climate but does not reach as high as $Q$. semecarpifolia. Quercus glauca grows in wet and warm areas between $500 \mathrm{~m}-3100 \mathrm{~m}$ (Malla et al. 1976, 1986; Press et al. 2000). Because of their key role in the vegetation it is essential to distinguish fossil pollen of different Pinus and Quercus species (Nakagawa et al. 1996). It is possible to identify the Pinus spp. under LM because there are only two species exist in Nepal. Among them Pinus wallichiana is haploxylon and Pinus roxburghii is diploxylon. The haploxylon variety contains dot marks in leptoma area while the diploxylon lacks such marks. However for the identification of Quercus pollen to species level it is essential to use the SEM (Ferguson et al. 2007).

The Patan Formation reveals warm and humid climate condition with the significant presence of subtropical gymnosperm such as Pinus roxburghii, subtropical angiosperms such as Castanopsis and oaks species such as Quercus lanata and Quercus leucotricophora except in the middle part of the section. The percentage of Pinus was less than $10 \%$ (insignificant) except in the middle part of the section. The other gymnosperms such as Picea, Abies and Tsuga all were hardly found to be exceeded by $1 \%$ in the total sum which is very insignificant for any climatic interpretation. The woody angiosperms were dominated by Quercus spp. mainly $Q$. lanata, $Q$. leucotricophora and $Q$. lamellosa. Subtropical tree such as Castanopsis present $2 \%$ of the total pollen sum, it is showing its presence throughout the section. Castanopsis is the chief element of the modern subtropical SchimaCastanopsis forest. Earlier studies have shown that the older Thimi Formation absent Castanopsis pollen. However the Gokarna Formation which is older than Thimi Formation, the Castanopsis pollen attains their presence up to $37 \%$ in the total pollen count (Paudayal 2005, 2006). It appears that the cold temperate climate existed during the Thimi Formation changed to warm, humid and subtropical to warm temperate climate during the deposition of the Patan Formation.

In pollen assemblage zone PATAN-I Quercus spp. (Q. lanata, Q. leucotrichophora and Q. lamellosa) attain $40 \%$, indicating a relatively warm climate. In PATAN-II Pinus wallichiana increases together with Quercus semecarpifolia and therefore indicates a shift to a warm temperate climate. In PATAN-III a reduction in Quercus is accompanied by an increase in Pinus roxburghii (insignificant), indicating a return to warmer climates. The climatic condition during the deposition of the Patan Formation was similar to that of the Gokarna Formation. The trend to present climate has started during the deposition of the upper part of the Patan Formation or afterwards.

\section{ACKNOWLEDGEMENTS}

I am grateful to the Austrian Academic Service (ÖAD) for providing fellowships to carry this research at Institute of Palaeontology, Vienna University, Austria. I am also grateful to David Ferguson, Reinhard Zetter and Chirsta Hofmann for their support and encouragements. I would like to thank Ishan Gautam (Natural History Museum, Tribhuvan University, Kathmandu) and Bandana Samant (Department of Geology, RTM Nagpur University, India) for reviewing the manuscript and providing fruitful comments. Thanks are extended to Ranjan Dahal and Arjun Aryal for providing drill core samples for this study. 


\section{REFERENCES}

Bhandari, S. and Paudayal, K. N., 2007. Palynostratigraphy and palaeoclimatic interpretation from the Plio-Pleistocene Lukundol Formation of the Kathmandu Valley, Nepal. Jour. Nepal Geol. Soc., v. 35, pp. 1-10.

Birks, H. J. B. and Gordon, A. D., 1985. Numerical Methods in Quaternary pollen analysis. Academic Press, London, 317p.

Bos, J. A. A., 1998. Aspects of Late glacial-Early Holocene vegetation development in western Europe, palynological and palaeobotanical investigations in Brabant (The Netherlands) and Hessen (Germany). LPP Foundation, Utrecht, 240 p.

Ferguson D. K., Zetter R., Paudayal, K. N., 2007. The need for the SEM in Palaeopalynology, Comptes Rendus Palevol, 6 (6-7), pp. 423-430. http://dx.doi.org/10.1016/j.crpv.2007.09.018

Franz, H. and Kral, F., 1975. Pollenanalyse und Radiocarbondatierung einiger Proben aus dem Kathmandubecken und aus dem Raum von Jumla in Westnepal. Sitz. Ber. Öst. Akad. Wiss.,math. Nat. Kl. Abt. I, Bd. 184, 1-5, pp. 9-17.

Fujii, R. and Sakai, H., 2001. Palynological study of the drilled sediments from the Kathmandu Basin and its palaeoclimatic and sedimentological significance. Jour. Nepal Geol. Sci. v. 25, Sp. issue, pp. 53-61.

Fujii, R. and Sakai, H., 2002. Paleoclimatic changes during last 2.5 Myr recorded in the Kathmandu Basin, central Nepal Himalaya. Jour. Asian Earth Sci., v. 20, pp. 255-266. http://dx.doi.org/10.1016/S13679120(01)00048-7

Igarashi, I., Yoshida, M. and Tabata, H., 1988. History of Vegetation and Climate in the Kathmandu Valley. Proc. Indian Natn. Sci. Acad., 54A(4), pp. 550-563.

Kral, F. and Havinga, A. J., 1979. Pollenanalyse und Radiocarbodatierung an Proben der oberen Teile der Sedimentserie des Kathmandu-Sees und ihre vegetationsgeschichtliche Interpretation. Sitz. Ber. Öst. Akad. Wiss., math. Nat. Kl. Abt. I, 188(1-10), pp. 45-61.

Malla, S. B., Shrestha, A. B., Rajbhandary, S. B., Shrestha, T. B., Adhikari, P. M. and Adhikari, S. R., (Eds.), 1976. Flora of Langtang and cross section vegetation survey (central zone). His Majesty's Government, Ministry of forest and soil conservation, Department of medicinal plants, Kathmandu, Nepal, 269p.

Malla, S. B., Rajbhandary, S. B., Shrestha, T. B., Adhikari, P. M., Adhikari, S. R. and Sakya, P. R., (Eds.), 1986. Flora of Kathmandu Valley. His Majesty's Government, Ministry of forest and soil conservation, Department of medicinal plants, Kathmandu, Nepal, 961p.

Moore, P. D., Webb, J. A. and Collinson, M. E., 1991.
Pollen Analysis. Blackwell Scientific Publications, $216 \mathrm{p}$.

Moribayashi, S. and Maruo, Y., 1980. Basement topography of the Kathmandu Valley, Nepal-An application of gravitational method to the survey of a tectonic basin in the Himalayas. Jour. Japan Soc. Engg. Geol., 21, pp. 30-37.

Nakagawa, T., Yasuda, Y. and Tabata, H. 1996. Pollen morphology of Himalayan Pinus and Quercus and its importance in palynological studies in Himalayan area. Review of Palaeobotany and Palynology, v. 91, pp. 317-329. http://dx.doi.org/10.1016/00346667(95)00072-0

Paudayal, K. N. and Ferguson, D. K., 2004. Pleistocene Palynology of Nepal. Quaternary International, v. 117, pp. 69-79. http://dx.doi.org/10.1016/S10406182(03)00117-4

Paudayal, K. N., 2005. Late Pleistocene Pollen Assemblages from the Thimi Formation, Kathmandu valley Nepal. The Island Arc, v. 14 (4), pp. 328-337. http://dx.doi.org/10.1111/j.1440-1738.2005.00490.x

Paudayal, K. N., 2006. Late Pleistocene Pollen Assemblages from the Gokarna Formation, Kathmandu valley, Nepal. Jour. Nepal Geol. Soc., v. 33, pp. 13-18.

Press, J. R., Shrestha, K. K., Sutton, D. A., 2000. Annotated checklist of flowering plants of Nepal. British Museum of Natural History, London, 430 p.

Sakai, T., Gajurel, A. P., Tabata, H., Ooi, N., Takagawa, T., Kitagawa, H., Upreti, B. N., 2008. Revised lithostratigraphy of fluvio-lacustrine sediments comprising northern Kathmandu basin in central Nepal. Jour. Nepal Geol. Soc., v. 37, pp. 25-44.

Stainton, J. D. A., 1972. Forests of Nepal. John Murray, London, $181 \mathrm{p}$.

Vishnu-Mittre and Sharma, C., 1984. Vegetation and climate during the last glaciation in the Kathmandu Valley, Nepal. Pollen et Spores, v. 26(1), pp. 69-94.

Yonechi, F., 1976. A preliminary report on the geomorphology of Kathmandu Valley, Nepal. Sci. Rept. Tohoku Univ., 7th. Ser., 23, pp. 153-161.

Yoshida, M. and Igarashi, Y., 1984. Neogene to Quaternary Lacustrine Sediments in the Kathmandu Valley, Nepal. Jour. Nepal Geol. Soc., v. 4, Sp. issue, pp. 73-100.

Yoshida, M. and Gautam, P., 1988. Magnetostratigraphy of Plio-Pleistocene lacustrine deposits in the Kathmandu Valley, central Nepal, Proceedings of Indian Natural Science Academy, v. 54A(30), pp. 410-417.

Zetter, R., 1989. Methodik und bedeutung einer routinemäßig kombinierten lichtmikros-kopischen und raster elektronenmikroskopischen untersuchung fossiler mikrofloren. Cour.Forsch.-Inst. Senckenberg, Frankfurt am Main, 109, pp. 41-50. 